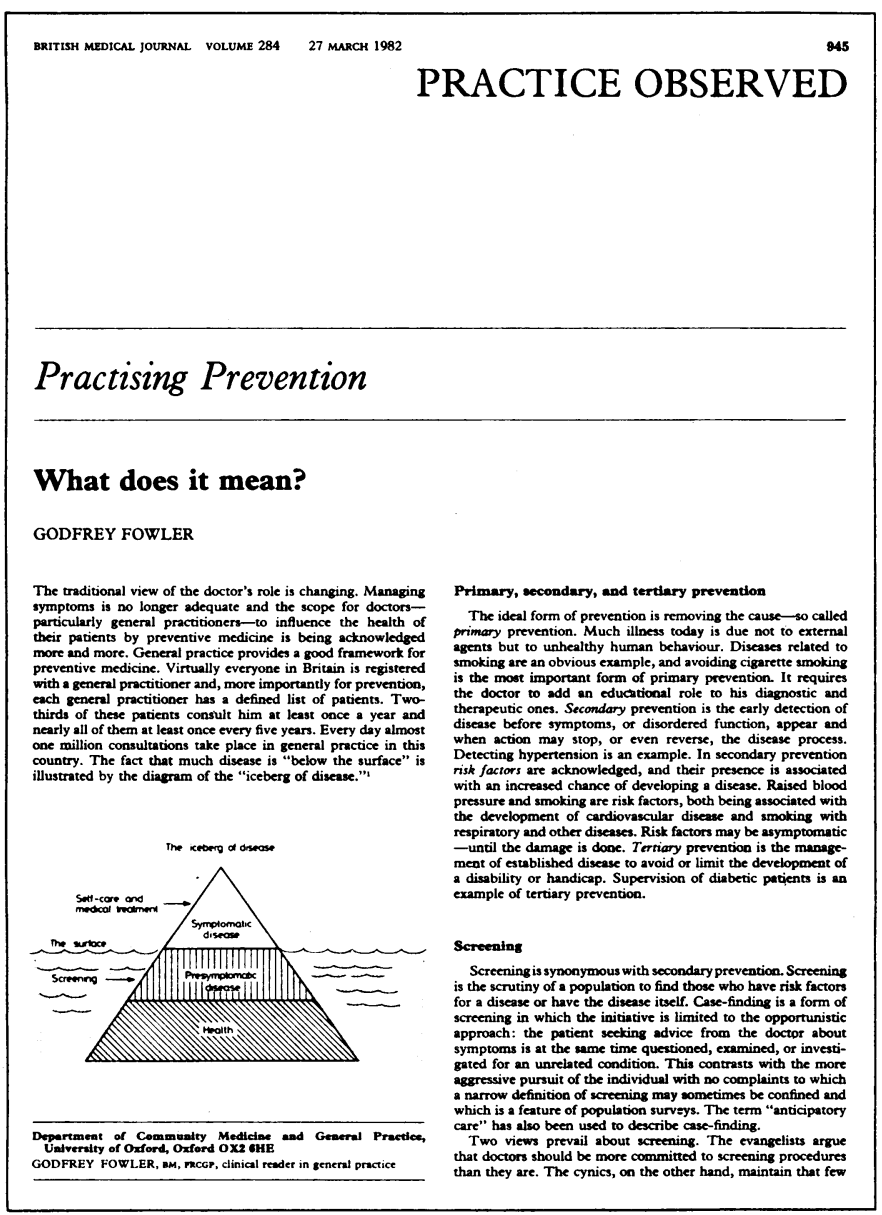

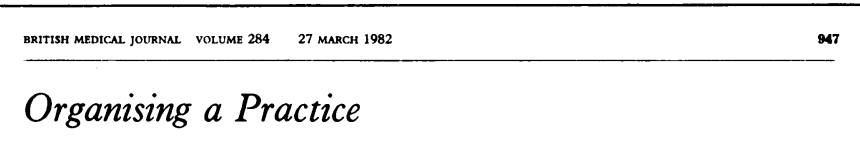

\title{
Advantages of deputising services: a personal view
}

J S K STEVENSON

By the summer of 1977 had completed 22 years in practice and

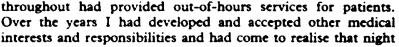

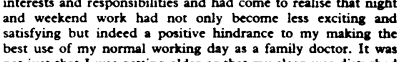
not iust that I was getting older or that my sleep was disturbed
that made me hate being on call but the fact that I could ne convince myself that it was imporant for my paticnst hat
should personally take my turn on the night and weckend rota.

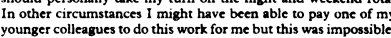
so the alternative was to use a

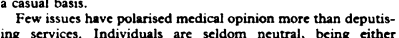

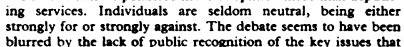

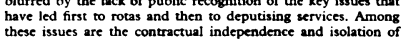

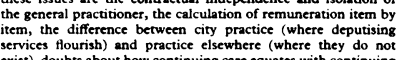

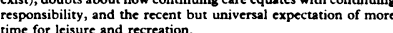

The debate so far

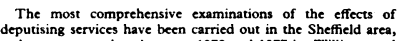

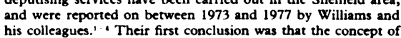
personal doctoring was not being threatened. Secondly, through
out the period, despite the increasing usce of depuitising

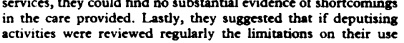

could be lifited.
Fry criticed the first Sheffield report on the grounds that

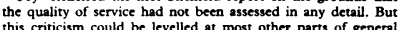
this criticism could be levelled at most other parts of general
practice and indeced Fry's own case azinst deputising services, although expresesed with conviction, relied on praditional opinion
without producing the envidence io condemn. Criticiems have

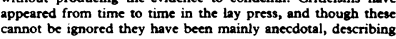



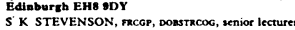

\section{6

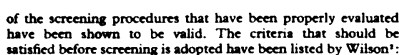

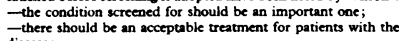

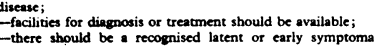 thage;

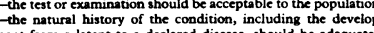

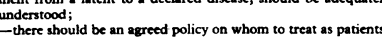

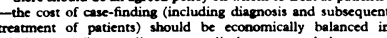

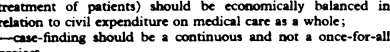
Etwical conedderatonoss

Screening and case-finding impose obligations on the doctor
over and above those to which he is normally subiect. In the

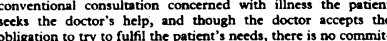

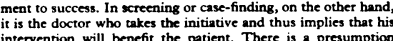

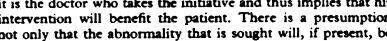

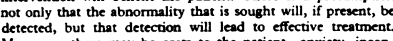

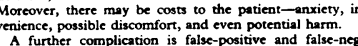

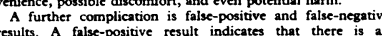

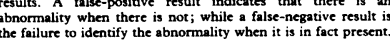

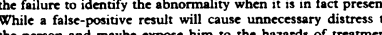

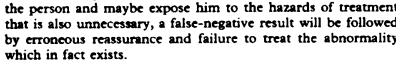

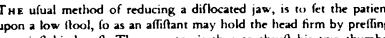

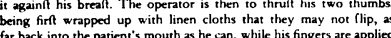

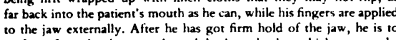

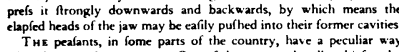

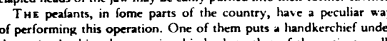

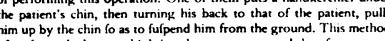

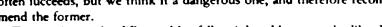

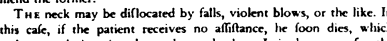

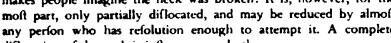

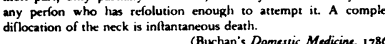

BRTTISH MEDICAL JOURNAL VOLUME $284 \quad 27$ MARCH 1982 Preventive medicine in the nineteenth century was based

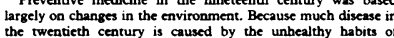
individuals modern prevention depends on achieving changes i buman bechaviour. Smoking, overeating, alcobol abuse, lack
exercisise, and accidents are major contributors to morbbidity and
mortality. Health education is the first step in achieving health mortality. Healch education is the first step in achieving healthy
behaviour. Cynics may dispute the effectiveness of health behaviour. Cynics may dispute the effectiveness of heal
education in producing healthy behaviour, but there is accumu-
lating evidence of such effectiveness. General practitioners ma lating evidence of such effectiveness." General practitioners may remind themselves that the word "doctor" means teacher and
that "o fall the many and varied sources of health informatio

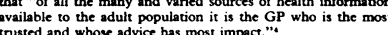

Role of the GP

There can be little doubt that if preventive medicine is worth while general practice provides important opportunities
practise it. The GP and his team are available and accessible to the vast majority of the population. Most importandly they have themselves, yet whose needs are the greatest. The credibility of a GP's advice is high and he role or heall all the more important. Continuity of care-the continuings
relationship between the general practitioner and the paticnt-
is as important to preventive as it is to therapeutic medicine.

References

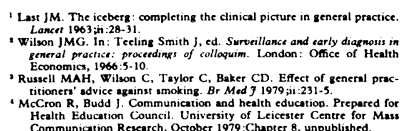


carcelifnefs. Children ought carly to be cautioned againt eating any

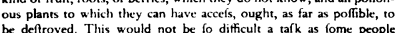
magine.
Poisonous planss have no doubr their ufe, and they ought to be cartle, they fhould be rooted out of all papture-grounds. They ought
likewife, for the fafery of the human ipecies, to be deftroyed in the

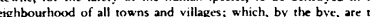
places where they mof commonly abound. 1 have feen the poifonous
lemlock, henbanc, wolfsbane, and deadly night-fhade, all krowing

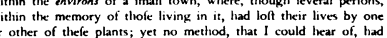

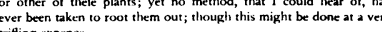
(Buchan's Domestic Medicine, 1786,
248

calls was the oldest doctor, and he had been longest in the On the basis of this review I decided that our patients might
well be berter served well be betrer served out-of-hours by a deputy rather that
myself. On 1 September 1977 I herefore started to employ
deputy to do my share of night and werkend work. favour of deputising services is supported by the experience
the next three years when I monitored the work underaken

Reaults of uaing a deputy for three years

Between September 1977 and August 19801 engaged a deputy
for the hours 1900 to 0700 for each week night 1 was on call and for the hours 1900 to 0700 for each week night $I$ was on call and
between 12 noon S Saturday and 0700 hours Monday when I was
on call at weekends. For the first year (September 1977 to August 1978$)$ I Ittempted to visit and reasspess, eether on the
same or on the following day, each of the 76 patients seen on same or on the following day, each of the 76 patents seen on
my behalfe. Threc of the 76 patients were edmitted to hospita
by the depury and three were referred to the local accident and emergency department for $x$-ray after minor trauma. Of the
remaining 70 patients, 13 were not at home when I visited and remaining 70 patients, 13 were not at home when I visited and
were not seen again during that episode of illness; 40 required no further follow-up; eight required further visiting in their
home by mysclif or one of my parteners; and nine subsequenty
atrended surgery during the same episode. Thus 53 (70\%) of the 76 patents seen by the deputy required no further forlow-up
during their episode of ilthess. Only one patient- - previously
known in the practice as being "difficult"- was dissatisfed with

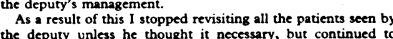
the depury unless he thought it necessary b but continued to
record facts about the deputising service either to confirm or

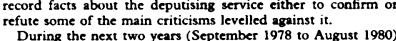
a furring t 138 patients were visited by her deputy. Added to the previous 76 patients this made a total of 214 deputy visits.
Twenty-four per cent of calls were for children between the
ages of 0 and 5 years, though they represented only $10^{\circ}$ of the ares of 0 and 5 years, though they represented only $10 \%$ of the
practice population. There were no other significant differences practice population. There were no other significant differens
in the "expected" distribution of requests sy age or sex. Using
information from the records of all 214 patients I examined five

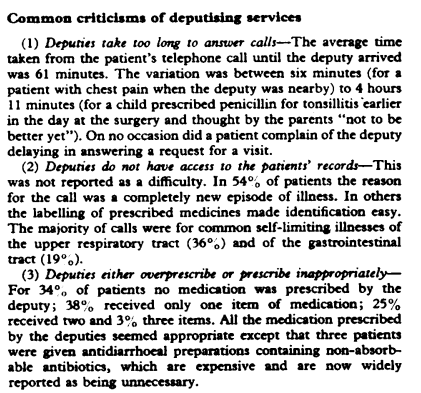

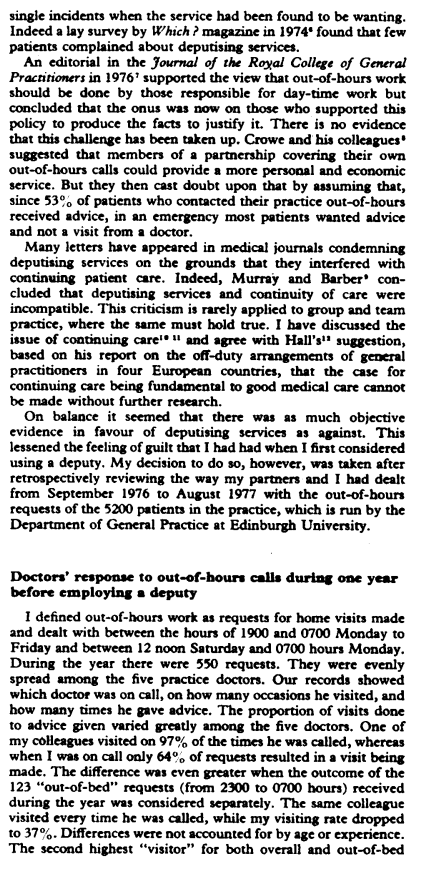

BRTTISH MEDICAL JOURNAL VOLUME $284 \quad 27$ MARCH 1982 (4) The parient does not see his regular doctor-To examine this
criticism I defined a patient as having a regular doctor if he or she had seen that doctor on six or more occasions in the previous
10 contacts. On this basis, $11 \%$ of the 214 patients visited by a 10 contacts. On this basis, $11 \%$ of the 214 patients visited by a
deputy in my behalf had a regular doctor but, as would be
expected, for only one fifth of these was the regular myself.
(5) Deputies interrupt the patient's contimuing care-To answer this criticism I again examined the patients' records to find out
which doctors had been concerned in the previous fuve bontacts which doctors had been concermed in the previous five contacts
with the 214 paticents: $60 \%$ of the patients had not been seen
by me at any of their five previous contacts; 18 of the patients by me at any of their five previous contacts; 18 of the patients
had been seen by five different doctors; $73 \%$ had been seen by at least three doctors. Only six patients had seen the same doctor at all five previous contacts ( 1 was the doctor concerned for only
one of these), and 14 patiens had not been long enough in the practice to have had five contacts.
It is true that our practice is atypical, being staffed to take since many "full-time" doctors also have activitices that take them
outside their practices during the day and join with others to form rotas for night and weecend cover the end result may be
the same in "average" practices.

Deputy's work load

During the threc years of the study a deputy acted as my
locum on 125 nights and 23 weekends. On 55 (44\%) weck-nights there were no requests for visits. On 54 nights a depury did one
visit, on 14 nights two visits, and on two nights four visits. Forty-nine visits were done on Saturdays and 75 on Sundays. hours. Advice was given or requested on $23(10 \%)$ occasions without a visit being made; six of these were berween 2300 and

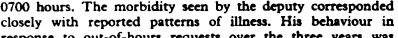
response to out-of-hours requests over the three years was
matched with that of the other four practice doctors and showed that the deputy ranked second highest in the proportion of visits

Cost of employing a deputy

Our practice was reckoned to be of a size that would normally support three doctors and I was charged by Air Call as a casual
user on this basis. Each night was charged as a single unit and
each weekend as three uniss. During the three years of this study 2. deputy was therefore acting for me on 194 units of time
$(125+(3 \times 23))$. In addition there was a surcharge for every visit made between 2300 and 0700 hours. All charges were subject to an annual increase throughout the period.
The total cost over the three years was 61581 . This could be
. The total cost over the three years was $\mathcal{L} 1581$. This could be
broken down as follows: $\mathcal{6} 6.67$ for cach time that either a visit
wass made or advice given, or $\{7.40$ for each visit made, or $\mathcal{K} 8.15$

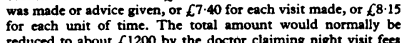
reduced to about 61200 by the doctor claiming night visit feet
for the 43 qualifying visits, and in addition the 61200 would be

Concluation

The publication in 1978 of a code of practice for deputising services's and the introduction of professional advisory commit-
tees to oversee these has meant that all deputising services are

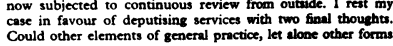

